\title{
ON THE OCCURRENCE OF NEUROPATHIC ARTHROPATHIES IN PERNICIOUS ANAEMIA
}

\author{
BY
}

\author{
PENTTI I. HALONEN and KLAUS A. J. JÄRVINEN
}

\section{From the Third Medical Clinic of the University of Helsinki* and from the Hospital of the Wihuri Research Institute}

Among the admissions to our clinic there was a case of severe anaemia perniciosa myelosis (subacute combined degeneration of the spinal cord) associated with painless joint disease. The tendon reflexes of the lower limbs were lost, there was considerable decrease in pain sensibility and deep sensibility, and the gait was markedly ataxic. The $x$-ray findings revealed alterations in the joints, and particularly in the knee bone a close resemblance to neuropathic joint changes. These alterations suggested to the radiologist that tabes dorsalis might be present in this case. Since the possibility of tabes was excluded by thorough examination, the suspicion arose that the patient's joint changes, which so closely resembled neuropathic ones, might be attributed to myelosis funicularis.

As we have not been able to find in the literature descriptions of joint deformation associated with anaemia perniciosa myelosis, we consider a presentation of our investigation of this problem to be justified.

\section{Discussion on Anaemia Perniciosa Myelosis}

It is known that pernicious anaemia often presents degenerative changes in the spinal cord, which condition is called myelosis funicularis. Data yielded by detailed histological examination and presented in various textbooks give evidence of patho-anatomical alterations in the spinal cord in up to 90 per cent. of cases of pernicious anaemia. Clinical evidence of myelosis is markedly less frequent, being present, according to various authors, in from 8 to 30 per cent. With regard to their location and histological picture, these changes -which may be very pronounced-bear resemblance to tabetic changes in the spinal cord. Also the clinical picture of perniciosa myelosis is similar to

* Director, Professor Östen Holsti, M.D. that of tabes. The literature actually points out the tabetiform manifestations of perniciosa myelosis. The fact being that the spinal alterations in perniciosa myelosis and the clinical picture of this condition bears such close resemblance to the corresponding changes and signs in tabes, it seems reasonable to assume that perniciosa myelosis also might present changes in the joints similar to those in tabes. This belief is given additional support by the observation that the lesion of the spinal cord does not seem to be of necessity a strictly specific one in order to produce a neuropathic joint lesion. The literature describes cases in which spinal changes, due to a variety of causes, are responsible for this type of joint lesion: for example, traumatic or subacute myelitis, trauma from tumour, or constant compression of the spinal cord resulting from tuberculous spondylitis. It has been found that even a peripheral nerve lesion or cerebral paralysis has led to such a joint lesion (Pribram, 1902). Neurogenic arthropathy has also been found associated with diabetic neuropathy (Forster and Bassett, 1948). In addition to tabes, we may possibly mention syringomyelia as the best known of all the agents of neuropathic arthropathies.

\section{Material of the Present Investigation}

Our material consists of fifty-two established cases of pernicious anaemia. Most of these patients have received repeated hospital care. Clinical symptoms of myelosis were present in twelve. All syphilitic patients have been exclude from the material by careful histories and by repeated blood analysis, as well as by liquor tests in cases of myelosis. All patients were subjected to systematic $x$-ray examinations of the knee and hip joints. The distribution of our material and the revealed joint changes are shown in Tables 1 and 2. 
TABLE 1

CASES OF PERNICIOUS ANAEMIA WITH NO SIGNS OF MYELOSIS FUNICULARIS

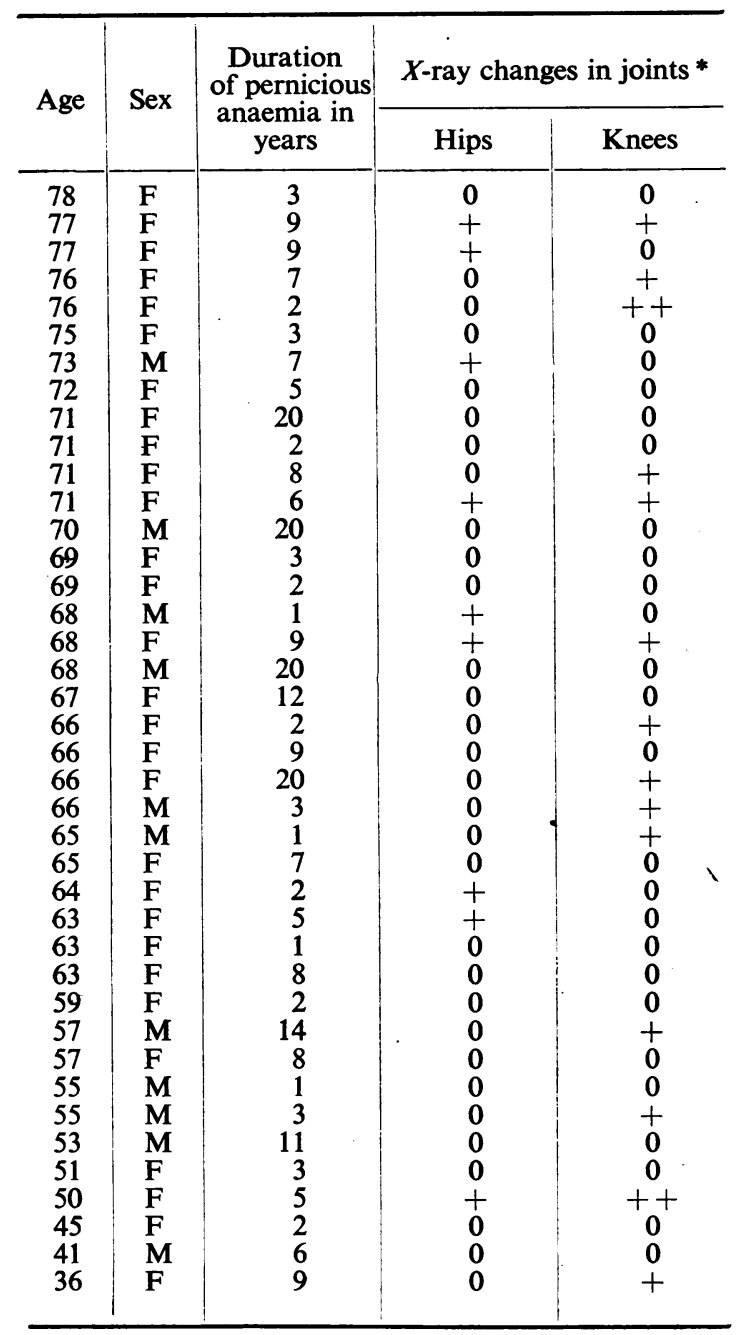

* The joint changes have been assessed as follows:

O No pathological changes in the joints.

+ Changes considered to be manifestations of mild osteoarthritis.

++ Marked changes of osteo-arthritis.

+++ Excessive joint changes. Severe manifestations of osteoarthritis with additional presence of loose fragments in the vicinity of the articular surfaces. The interarticular space is, as a rule, markedly narrowed or entirely lost. There may be a tendency toward subluxation of the joints.

We have attempted to make the classification of the $x$-ray findings showing the various degrees of alteration as objective as possible by letting the radiologist carry out the grouping only on the basis of the radiographs presented to him, without any information whatever about the clinical examinations.

\section{Discussion of our Findings}

As will be seen from the two Tables, it is in cases of myelosis funicularis that joint changes most frequently occur, and indeed all the most serious changes in the knee joint fall into the group of severe myelosis. Quite naturally our patients, most of whom were old people (the average age of those without myelosis being 64 years, those with mild myelosis 63 , and those with severe myelosis 66 years) also presented changes in the joints attributable to other causes, particularly to simple osteo-arthritis of old age. The frequency of the joint changes and the severity of the alterations in the knee joints being appreciably greater in the group with myelosis than in those with other types of pernicious anaemia (according to the control material), we find it reasonable to assume that the condition of myelosis funicularis and the presence of joint changes bear a causal relation to each other. For the reasons offered above the theory of a neuropathic aetiology for these changes seems justified. This view is supported by the frequency of joint changes in perniciosa myelosis, by their scarcity in other types of pernicious anaemia, and particularly by the $x$-ray picture of the extreme changes concerned, which is similar to those of other known cases of neuropathic arthropathies: severe changes of osteo-arthritic type, the appearance of osteophytes, marked narrowing of the interarticular space, loose fragments found in the vicinity of the joint surfaces, and a tendency to develop subluxation (Figs. 1 and 2). We do not consider that the fact that the joint changes described do not appear in every single instance of myelosis contradicts our view (in two serious cases of myelosis there were no recognizable changes in the joints). Tabes and syringomyelia, for instance, as far as we know, present simultaneous severe neuropathic joint changes relatively seldom.

A view generally held, and confirmed particularly by animal tests (Katsuki, 1936), is actually that a lesion of the nerve fibres alone cannot be responsible for neuropathic arthropathies. Additional agents, such as local trauma, metabolic disorder, etc., are needed to produce them. We think it has not been possible to carry out an analysis of such additional factors on account of the scanty material available.

The clinical picture of extensive joint changes appearing in the knees in the more severe instances of myelosis is one of marked thickening of the knee joints and, on flexion, crepitation louder than usual.

More pronounced motor disturbances have not been encountered. In one of the cases of this group occasional locking of the kneee joints occurred 
TABLE 2

I

CASES OF PERNICIOUS ANAEMIA WITH SIGNS OF MYELOSIS FUNICULARIS

\begin{tabular}{|c|c|c|c|c|c|c|}
\hline & \multirow{2}{*}{ Age } & \multirow{2}{*}{ Sex } & \multirow{2}{*}{$\begin{array}{l}\text { Duration of pernicious } \\
\text { anaemia in years }\end{array}$} & \multirow{2}{*}{$\begin{array}{l}\text { Duration of the signs } \\
\text { of myelosis funicularis } \\
\text { in years }\end{array}$} & \multicolumn{2}{|c|}{$\begin{array}{l}\text { Radiographic } \\
\text { changes in joints }\end{array}$} \\
\hline & & & & & Hips & Knees \\
\hline Group A & $\begin{array}{l}71 \\
70 \\
68 \\
61 \\
43\end{array}$ & $\begin{array}{l}\mathbf{F} \\
\mathbf{M} \\
\mathbf{M} \\
\mathbf{F} \\
\mathbf{F}\end{array}$ & $\begin{array}{r}8 \\
1 \\
6 \\
13 \\
19\end{array}$ & $\begin{array}{r}2 \\
1 \\
>2 \\
>1 \\
7\end{array}$ & $\begin{array}{l}0 \\
++ \\
+ \\
++ \\
+\end{array}$ & $\begin{array}{l}0 \\
+ \\
+ \\
+ \\
0\end{array}$ \\
\hline Group B & $\begin{array}{l}71 \\
69 \\
67 \\
66 \\
64 \\
64 \\
62\end{array}$ & $\begin{array}{l}\mathbf{F} \\
\mathbf{F} \\
\mathbf{F} \\
\mathbf{F} \\
\mathbf{M} \\
\mathbf{F} \\
\mathbf{F}\end{array}$ & $\begin{array}{r}>1 \\
17 \\
23 \\
10 \\
>3 \\
10 \\
>1\end{array}$ & $\begin{array}{r}{ }_{1} \\
>2 \\
2 \\
>_{5} \\
>_{3} \\
>_{1}\end{array}$ & $\begin{array}{l}+ \\
+ \\
+ \\
+ \\
+ \\
+ \\
+ \\
0\end{array}$ & $\begin{array}{l}+++ \\
++ \\
+ \\
+++ \\
+++ \\
+++ \\
0\end{array}$ \\
\hline
\end{tabular}

Group A.- Slight cases of myelosis funicularis with distinct reflex disturbances. As a rule, a marked uncertainty or loss of tendon reflexes in the lower extremities, and a distinct decrease of pain and deep sensibility. Walking fairly normal.

Group B.-The more serious forms of myelosis funicularis. Tendon reflexes of the lower extremities completely lacking. Walking distinctly ataxic. Pain and deep sensibility markedly decreased.

very late in the patient's history. Alterations in the hip joints in the presence of myelosis have, as a rule, produced no manifest ctinical symptoms. No painful joints have been seen in the presence of arthropathies associated with perniciosa myelosis and this is true of neuropathic joint lesions in general. It is the absence of pain symptoms that presumably explains the fact that, as far as we know, no attention has formerly been paid to these marked alterations in the joints.

Since, according to what has been said above, it seems reasonable to believe that neuropathic changes in the joints may develop pernicious anaemia associated with myelosis funicularis, we think it more justified than ever before to call attention to the prevention and treatment of myelosis funicularis.

\section{Summary}

Our investigations comprised fifty-two cases of pernicious anaemia, five of which showed mild myelosis funicularis and seven a severe type of the disease. Joint changes, particularly in the knees, were seen in the presence of myelosis, and the most extensive changes were found in the cases of severe myelosis. In two cases, however, no- or only slight-joint changes were seen. In cases without myelosis there were comparatively few and only mild joint lesions. In the opinion of the writers the joint changes detected are both clinically and radiologically of the type of neuropathic arthropathies.

\section{REFERENCES}

Ehrlich, P., and Lazarus, A. (1898). "Die Anaemie." Nothnagels spez. Path. Ther., vol. 8, Vienna.

Forster, D. B., and Bassett, R. C. (1947). Arch. Neurol. Psychiat., Chicago, 57, 173.

Katsuki, S. (1936). Z. klin. Med., 130, 567.

Pribram, A. (1902). " Chronische Gelenkrheumatismus und Osteoarthritis deformans." Nothnagels spez. Path. Ther., vol. 7, Vienna.

\section{Sur la Fréquence des Arthropathies Nerveuses dans l'Anémie Pernicieuse RÉSUMÉ}

Nos recherches ont porté sur cinquante-deux cas d'ané mie pernicieuse dont cinq présentaient une légère sclérose systématisée et sept une forme plus grave de la maladie. On a observé des lésions articulaires, particulièrement dans les genoux, chez les malades atteints de sclérose médullaire, et ce sont les sujets les plus gravement atteints qui présentaient les lésions les plus étendues. Deux malades ne présentaient cependant que des lésions articulaires très légères ou pas de lésions. Les autres cas d'anémie perniciéuse ne présentaient que des lésions articulaires relativement peu nombreuses et peu marquées. Les auteurs considèrent que les lésions articulaires observées appartiennent cliniquement et radiologiquement à la catégorie des arthropathies nerveuses. 

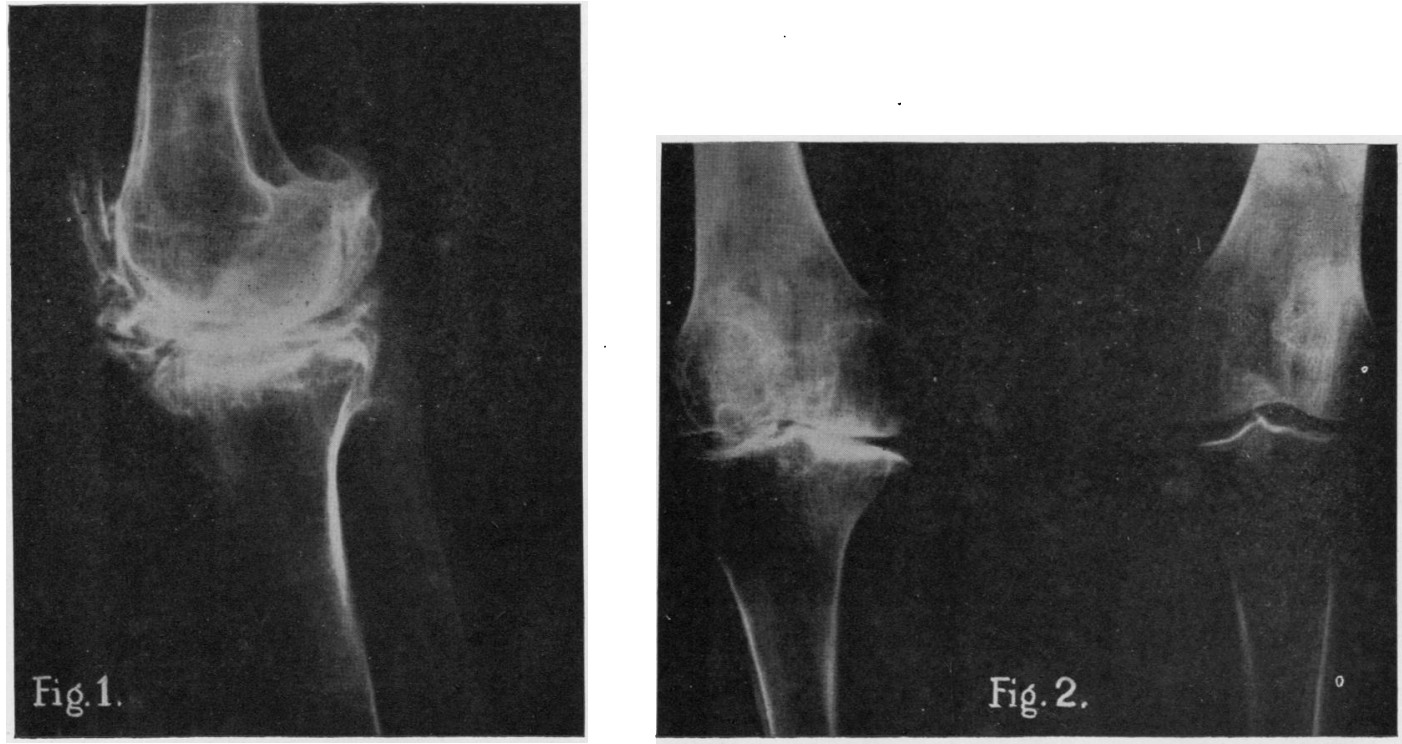

FIG. 1 and 2.-Radiographs of a patient, aged 66, who has been suffering from anaemia perniciosa for ten years and has had a strong myelosis funicularis for the last five years. There are severe changes of osteoarthritic type, especially in the right knee. Note also the appearance of osteophytes, marked narrowing at the interarticular spaces, and loose fragments in the vicinity of joint surfaces. 


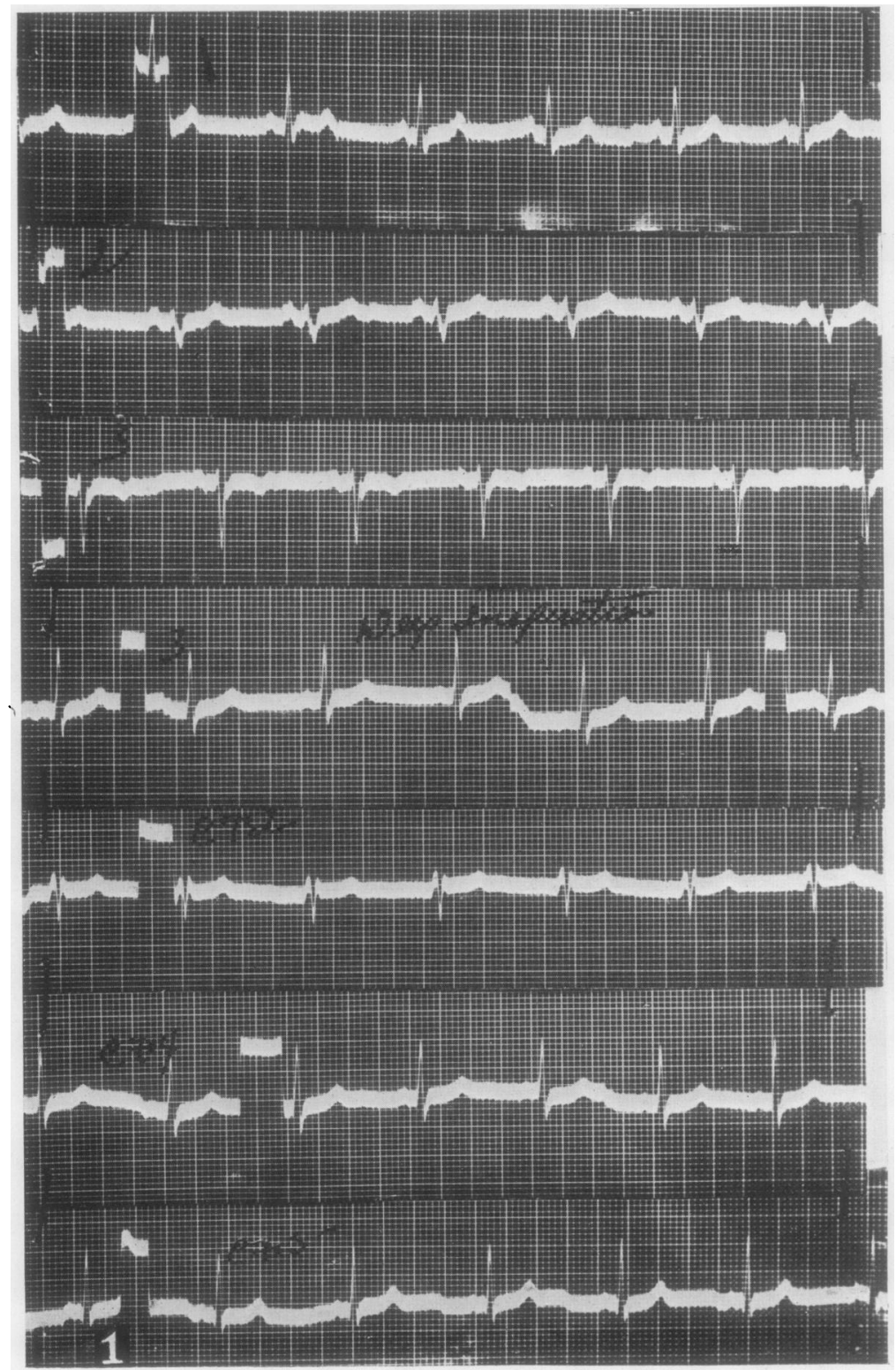

FiG. 1.-Electrocardiogram taken on July 3, 1947, showing left axis shift and a QRS duration of 0.11 second in lead II, but considered normal. 


$$
\text { ILLUSTRATIONS TO ARTICLE BY WOLFSON AND ALTER }
$$
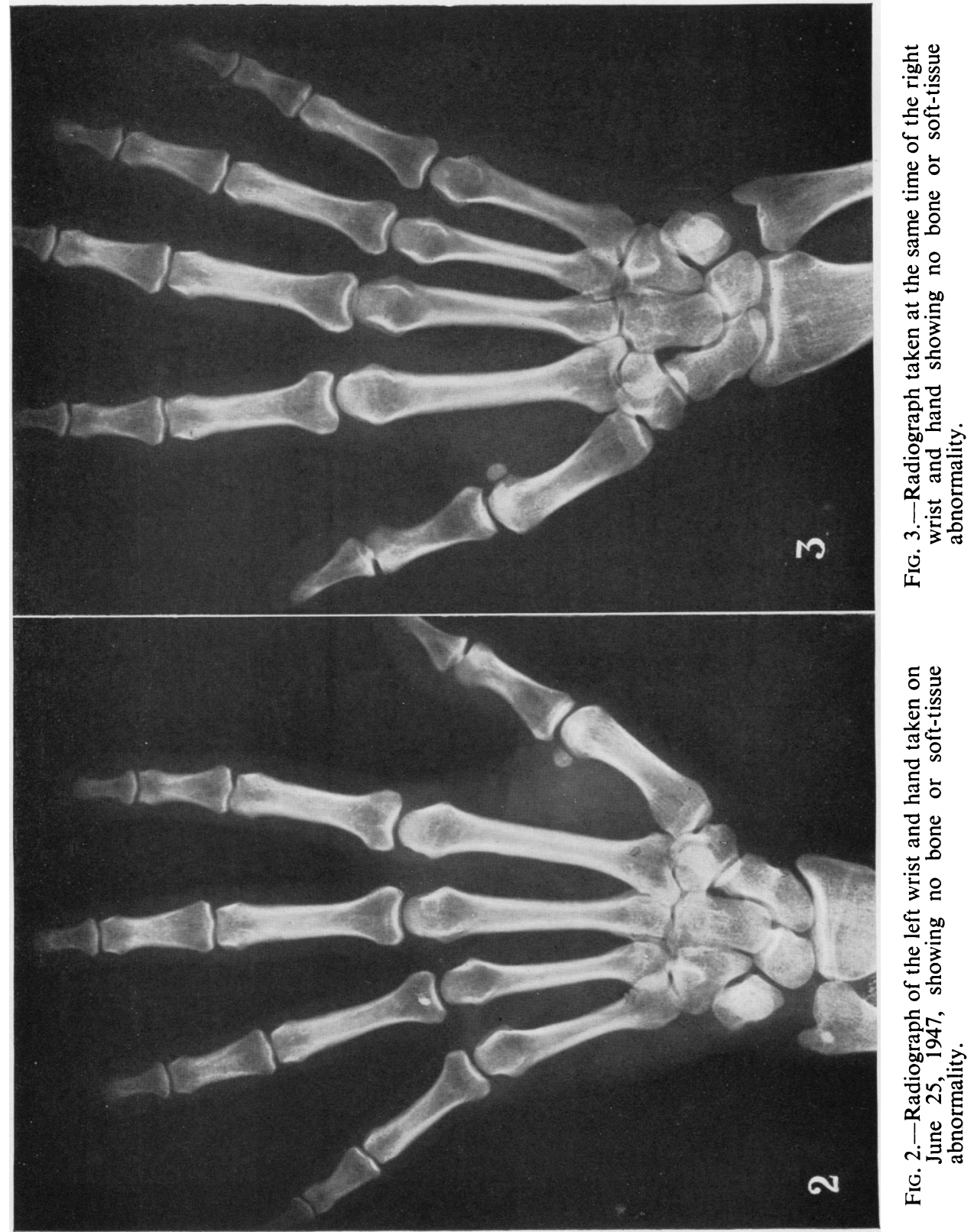

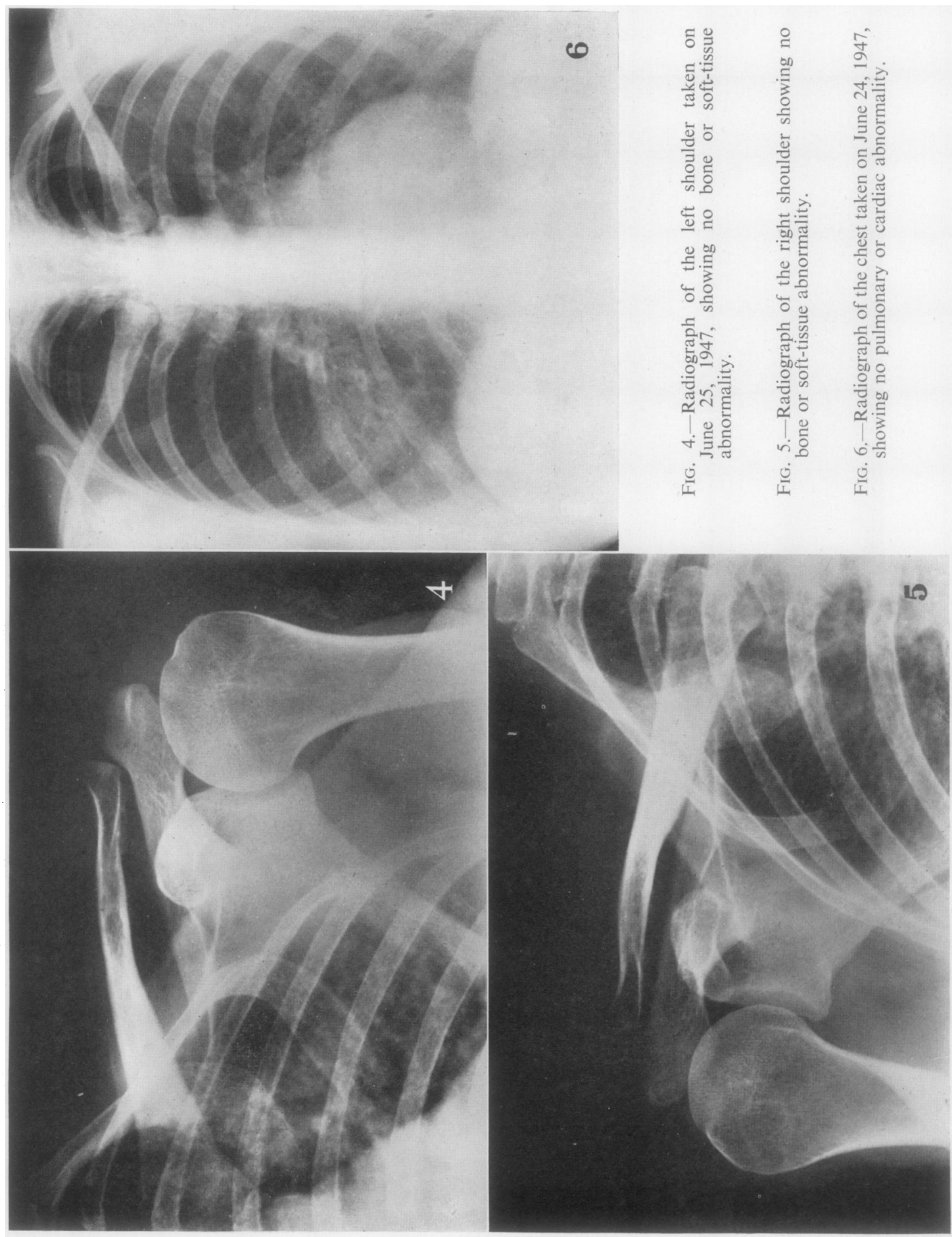